\title{
Knowledge, Attitudes and Practices of Health Care Workers on Ebola in Hospital Towards Ebola Virus Disease, Conakry, Guinea, 2016
}

\author{
Camara Alioune $^{1, ~ *}$, Diallo Ibrahima Sory ${ }^{2}$, Toure Abdoulaye ${ }^{1}$, Bayo Mouctar ${ }^{1}$, Douba Alfred ${ }^{3}$, \\ Guilavogui Timothé ${ }^{1}$, Traore Mohamed Sahar ${ }^{4}$, Sidibe Sidikiba ${ }^{1}$, Diallo Aissatou Taran ${ }^{5}$, \\ Konde Mandy Kader ${ }^{1}$ \\ ${ }^{1}$ Department of Public Health, University of Conakry, Conakry, Guinea \\ ${ }^{2}$ Institute of Nutrition and Child Health, Conakry, Guinea \\ ${ }^{3}$ Department of Public Health and Medical Informatics, University of Cocody-Abidjan, Abidjan, Ivory Coast \\ ${ }^{4}$ Department of Pharmacy, University of Conakry, Conakry, Guinea \\ ${ }^{5}$ Department of General Surgery, Ignace Deen National Hospital, University Hospital of Conakry, Conakry, Guinea \\ Email address: \\ aliounec@gmail.com (C. Alioune) \\ ${ }^{*}$ Corresponding author
}

To cite this article:

Camara Alioune, Diallo Ibrahima Sory, Toure Abdoulaye, Bayo Mouctar, Douba Alfred, Guilavogui Timothé, Traore Mohamed Sahar, Sidibe Sidikiba, Diallo Aissatou Taran, Konde Mandy Kader. Knowledge, Attitudes and Practices of Health Care Workers on Ebola in Hospital Towards Ebola Virus Disease, Conakry, Guinea, 2016. Central African Journal of Public Health. Vol. 4, No. 1, 2018, pp. 1-6. doi: 10.11648/j.cajph.20180401.11

Received: December 1, 2017; Accepted: December 14, 2017; Published: January 15, 2018

\begin{abstract}
To cope with any further outbreak of Ebola Virus Disease (EVD) in Guinea, a cross-sectional study was carried out to assess the level of awareness, attitude and practice of health care workers about EVD in Conakry, Guinea. A crosssectional study was conducted in the Institute of Nutrition and Child Health (INSE), at the national hospitals of Donka and Ignace Deen in 2016 and involved 14 clinical facilities. Scores were built up for knowledge, attitude and practice. These scores were classified into two groups: bad (score $<50 \%$ ) and good (score $\geq 50 \%$ ). A total of 267 participants from these health care systems responded to a structured questionnaire. The proportion of health care workers with good knowledge, attitudes and practices was respectively $71.9 \%, 94 \%$ and $50.2 \%$. Factors associated with good knowledge of EVD were male [Adjusted Odds Ratio (AOR): 1.7: 95\% CI 1.0 to 2.9] and received training in EVD (2.7: 1.6-4.8). Factors associated with good practice were membership in INSE (2.3: 1.1-4.7) and training on EVD (2.2: 1.3-3.8). There is lack of knowledge of EVD, as well as negative attitudes and practices, particularly in prevention. However, continuing education for health care workers could correct these deficiencies.
\end{abstract}

Keywords: Ebola Virus Disease, Knowledge, Health Care Workers, Guinea

\section{Introduction}

The EVD epidemic in West Africa in 2014 -2016 emerged in Guéckédou, Guinea [1,2] and was characterized by its high lethality and rapid spread to urban areas and neighboring countries [3,4]. A total of 28,616 confirmed, probable and suspect cases were reported in Guinea, Liberia and Sierra Leone, including 11,310 deaths [5]. In Guinea, this epidemic was unprecedented for both, health and socio- economic consequences [6, 7]. According to the World Health Organization, Guinea has recorded 3,811 cases including 2,543 deaths (case fatality rate of 67\%), 211 health workers were affected with 115 deaths [8]. The weakness of the health system, particularly the prevention and control of infection (PCI) measures in health facilities, have meant that health care workers must pay a heavy toll during this epidemic $[9,10]$. The isolation of the patients, the observation of hygiene measures and the use of personal 
protective equipment, the use of chlorinated solutions during the management process helped to avoid any spreading of the EVD in the health structures [11]. A good level of knowledge and practice of health care workers is essential to protect staff and prevent possible outbreaks [9, 10, 12]. During the EVD outbreak, the Ministry of Health, in collaboration with its partners, organized ICH training for several health facilities with supplies of PPE materials. During the epidemic, Touré [13] had shown that $84 \%$ of health care workers surveyed in Guinea in 2014 estimated their level of knowledge on the EVD was insufficient and $97.1 \%$ sought training. Since this work, there has been a lack of publication on the level of health care staff that face with the epidemic of EVD that may occur in Guinea. It was therefore necessary to carry out this study whose objective was to evaluate the level of knowledge, the attitude and the practice of the nursing staff towards the EVD.

\section{Materials and Methods}

\subsection{Study Setting}

The Institute for Nutrition and Child Health (INSE), the national hospitals of Donka and Ignace Deen were the study sites. This study was conducted from 27 January to 26 April 2016 and involved 14 clinical facilities including 6 at Donka (Psychiatry, Internal Medicine, Emergencies, Dermatology, Infectious Diseases, Paediatrics), 7 at Ignace Deen (Pneumology, Rheumatology, Haematology, Emergencies, Maternity, General Surgery, Traumatology) and INSE.

\subsection{Study Design and Population}

A cross-sectional study was conducted regarding the health care workers staff of the selected services (doctors, nurses and trainee doctors). Health care workers who completed the questionnaire with more than $10 \%$ of the missing data were excluded. The sampling was non-random and consisted of a reasoned choice targeting services with a high number of health care workers or having a high risk of exposure to Ebola virus disease (EVD).

\subsection{Data Collection and Study Instrument}

The technique of self-administration of a standardized questionnaire made it possible to collect information from the health care workers. The data collected included sociodemographic characteristics (age, sex, number of years of practice, employment status and membership structure). The questionnaire also collected information related to the type of training on Ebola, the knowledge, attitudes and practice of the nursing staff on EVD. Issues related to knowledge of the epidemiological, pathogenesis and clinical aspects of EVD. The questions about attitude were focused on reaction to suspect Ebola. Practical issues included handwashing techniques, wearing personal protective barriers, vaccination against EVD.

\subsection{Statistical Analysis}

Data were entered the EPI DATA (version 3.1) and analyzed using SPSS 24. The results were presented as a proportion for the categorical variables, and as a mean \pm standard deviation for the quantitative variables. A scale by assigning scores to the responses was constructed to assess the level of knowledge, attitude and practice of the health care workers. The answer to a question was rated 1 when it was right answer and 0 when it was wrong. A sum of scores was made for knowledge, attitude and practice. The level was classified into two groups: bad (score $<50 \%$ ) and good (score $\geq 50 \%$ ) [14]. A bivariate and multivariate logistic regression was performed to analyze the factors associated with a good level. Factors associated with $p \leq 0.10$ in univariable analysis were entered a multivariable logistic regression models, and factors associated with good level retained from backward selections. The tests were considered significant at the $5 \%$ level.

\subsection{Ethical Considerations}

Respondents were intimated of the goals and objectives of the study before they were recruited. No names were filled on the questionnaires. The questionnaires were given numbers to facilitate their entry and analysis and to ensure anonymity of the respondents.

\section{Results}

\subsection{Socio-Demographic Characteristics of Respondents}

In total, 550 health care workers were counted and 267 were interviewed (participation rate of $49 \%$ ). Table 1 shows the socio-demographic characteristics of the population studied. Most of health care workers surveyed were male $(56.2 \%)$, doctors preparing their thesis $(36 \%)$ with an average age of $29.8 \pm 6.8$ years and had received specific training on the Ebola virus disease $(65.5 \%)$.

Table 1. Characteristics according to the level of knowledges, practices and attitudes of health care workers at INSE, Donka and Ignace Deen in 2016.

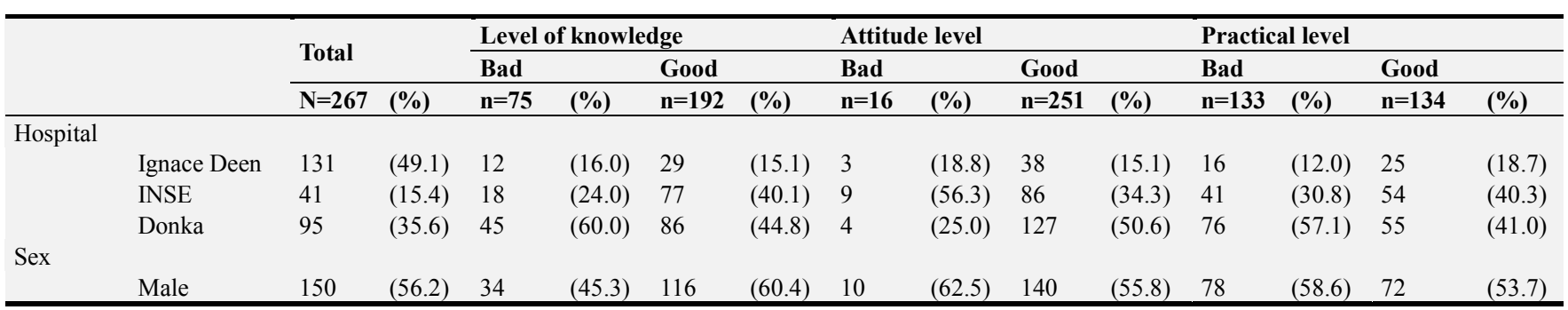




\begin{tabular}{|c|c|c|c|c|c|c|c|c|c|c|c|c|c|c|c|}
\hline & & \multirow{2}{*}{\multicolumn{2}{|c|}{ Total }} & \multicolumn{4}{|c|}{ Level of knowledge } & \multicolumn{4}{|c|}{ Attitude level } & \multicolumn{4}{|c|}{ Practical level } \\
\hline & & & & Bad & & Good & & Bad & & Good & & Bad & & Good & \\
\hline & & $\mathrm{N}=\mathbf{2 6 7}$ & $(\%)$ & $n=75$ & $(\%)$ & $n=192$ & $(\%)$ & $n=16$ & $(\%)$ & $n=251$ & (\%) & $n=133$ & $(\%)$ & $n=134$ & $(\%)$ \\
\hline & Female & 117 & $(43.8)$ & 41 & $(54.7)$ & 76 & (39.6) & 6 & $(37.5)$ & 111 & $(44.2)$ & 55 & (41.4) & 62 & $(46.3)$ \\
\hline \multicolumn{16}{|l|}{ Age range } \\
\hline & $\leq 28$ years & 111 & $(41.6)$ & 36 & $(48.0)$ & 75 & $(39.1)$ & 3 & $(18.8)$ & 108 & $(43.0)$ & 61 & (45.9) & 50 & (37.3) \\
\hline & $>28$ years & 156 & $(58.4)$ & 39 & $(52.0)$ & 117 & $(60.9)$ & 13 & $(81.3)$ & 143 & $(57.0)$ & 72 & (54.1) & 84 & (62.7) \\
\hline \multicolumn{16}{|c|}{ Professional status } \\
\hline & Doctor & 78 & $(29.2)$ & 16 & $(21.3)$ & 62 & $(32.3)$ & 6 & $(37.5)$ & 72 & (28.7) & 36 & $(27.1)$ & 42 & (31.3) \\
\hline & Nurse & 93 & $(34.8)$ & 30 & $(40.0)$ & 63 & (32.8) & 7 & $(43.8)$ & 86 & $(34.3)$ & 47 & (35.3) & 46 & (34.3) \\
\hline & Trainee doctor & 96 & $(36.0)$ & 29 & $(38.7)$ & 67 & $(34.9)$ & 3 & $(18.8)$ & 93 & $(37.1)$ & 50 & (37.6) & 46 & (34.3) \\
\hline \multicolumn{16}{|c|}{ Ebola training } \\
\hline & Yes & 175 & $(65.5)$ & 36 & $(48.0)$ & 139 & $(72.4)$ & 13 & $(81.3)$ & 162 & $(64.5)$ & 75 & $(56.4)$ & 100 & (74.6) \\
\hline & No & 92 & $(34.5)$ & 39 & $(52.0)$ & 53 & $(27.6)$ & 3 & $(18.8)$ & 89 & $(35.5)$ & 58 & (43.6) & 34 & $(25.4)$ \\
\hline
\end{tabular}

The training received was related to dressing techniques $(43.4 \%)$, patient sorting $(42.3 \%)$, management at the Ebola treatment center $(15 \%)$ and training of trainers $(7,1 \%)$.

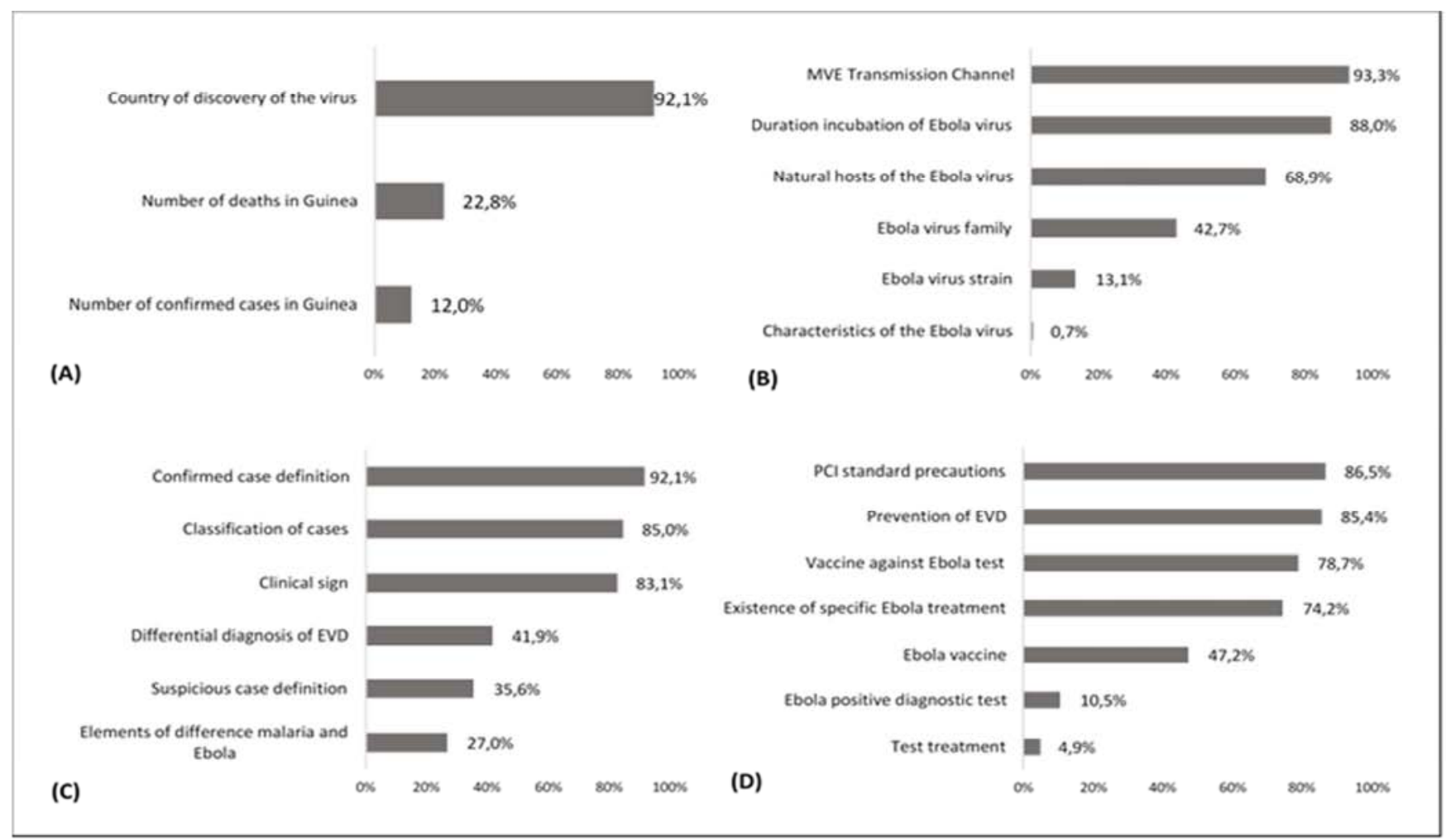

Figure 1. Percentage of knowledge questions in Epidemiology (A), Pathogenesis (B), Clinic (C), Prevention and Treatment (D) that were answered correctly by health care workers of INSE, Donka and Ignace Deen in 2016.

\subsection{Respondents Level of Knowledges, Attitudes and Practices of EVD}

The level of knowledge of the medical staff was considered good (score $\geq 50 \%$ ) for $71.9 \%$ of health care workers (Table 1). In terms of the knowledge assessed, the level was good for $28.1 \%$ on Ebola virus disease's epidemiology, $73 \%$ in pathogenesis, $81.6 \%$ in clinic aspect and for $64.4 \%$ in prevention and treatment. Figure 1 shows that knowledge was less good for questions regarding confirmed EVD cases (12\%), Ebola virus structure (0.7\%), differential diagnosis components of EVD and malaria
$(27 \%)$ and trials $(4.7 \%)$. Table 1 shows that the level of attitude was good for $94 \%$ of health care workers. However, $14 \%$ of participants reported expelling the suspect case because they did not go through a sorting center. This constitutes a deficiency. The caregiver's practices were considered as good for $50.2 \%$. The acceptance to take part in the vaccine trial $(14.6 \%)$, the duration of hand washing $(16.5 \%)$ and the principle of using gloves $(18.5 \%)$ were the practices with worst frequencies (Figure 2). 


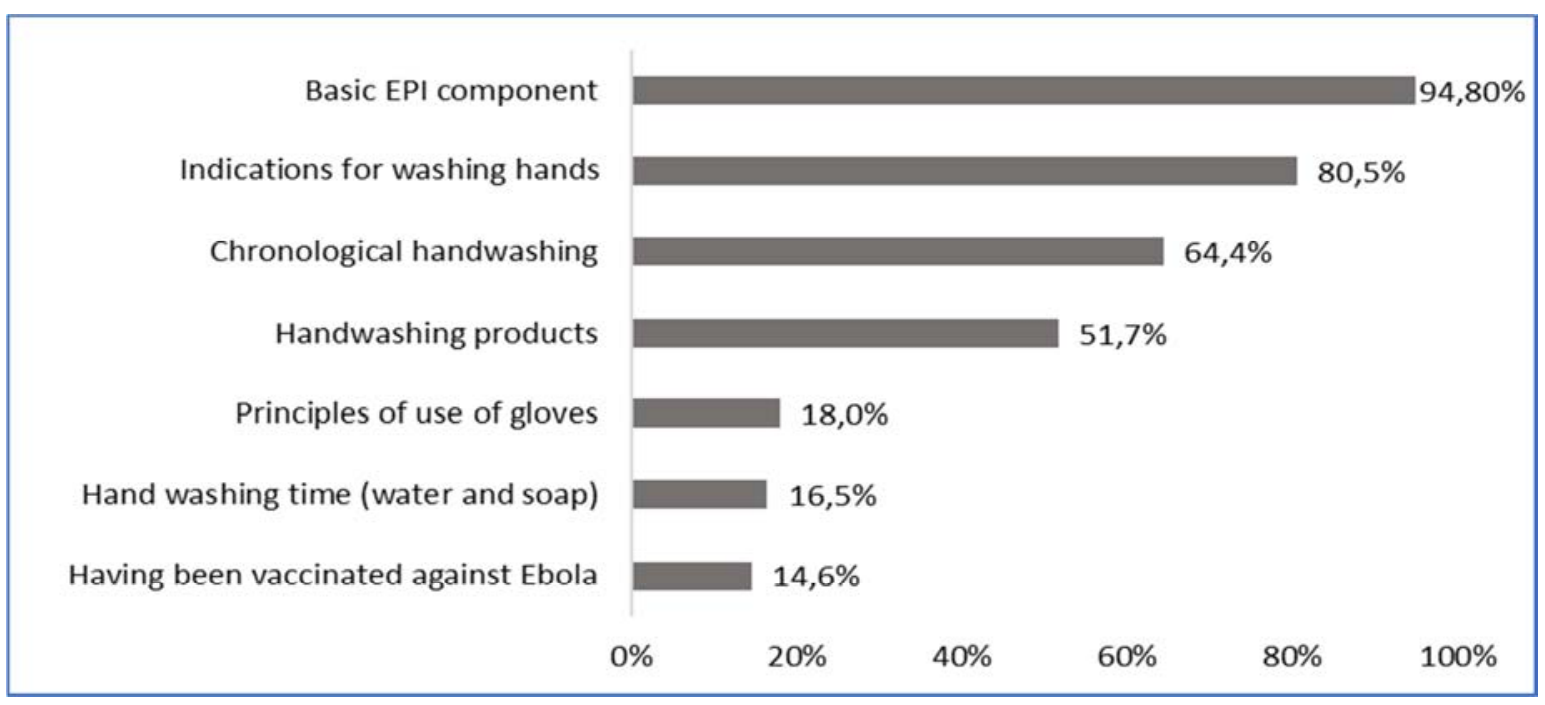

Figure 2. Percentage of practice questions answered correctly by health care workers of INSE, Donka and Ignace Deen in 2016.

\subsection{Factors Associated at Knowledges, Attitudes and Practices Level (CAP) of EVD}

The table 2 shows logistic regression outcome for the identification of factors associated with a good knowledge, attitude and practice regarding EVD. The multivariate analysis found that the factors associated with a good knowledge of EVD among male health care workers [Adjusted Odds Ratio (AOR): 1.7; 95\% CI: 1.0-2.9] and received training on EVD (AOR: 2.7, 95\% CI 1.6-4.8). The factors that remained independently associated with good practice among health care workers were membership of INSE (AOR: 2,3, 95\% CI: 1,1-4,7) and training on EVD (AOR: 2.2, 95\% CI $1.3-3.8$ ).

In this study, none of the factors tested were associated to the good attitude level of health care workers.

Table 2. Factors associated with the good levels of knowledge, practice and attitude of carers from INSE, Donka and Ignace Deen in bivariate and multivariate analysis in 2016.

\begin{tabular}{|c|c|c|c|c|c|c|c|c|c|c|c|}
\hline & \multicolumn{4}{|c|}{ Good level of knowledge } & \multicolumn{4}{|c|}{ Good level of practice } & \multicolumn{3}{|c|}{ Good attitude level } \\
\hline & $\mathbf{n}$ & $(\%)$ & OR $(95 \% \mathrm{CI})$ & $\operatorname{AOR}(95 \% \mathrm{CI})$ & $\mathbf{n}$ & $(\%)$ & OR $(95 \% \mathrm{CI})$ & $\begin{array}{l}\text { AOR } \\
(95 \% \text { CI })\end{array}$ & $\mathbf{n}$ & $(\%)$ & $\operatorname{AOR}(95 \% \mathrm{CI})$ \\
\hline \multicolumn{12}{|l|}{ Hospital } \\
\hline Ignace Deen & 86 & $(65.6)$ & $1-$ & & 55 & $(42.0)$ & $1-$ & & 127 & $(96.9)$ & 1 \\
\hline INSE & 29 & (70.7) & $1.3(0.6-2.7)$ & & 25 & $(61.0)$ & $2.1 *(1.1-4.4)$ & $2.3 * *(1.1-4.7)$ & 38 & (92.7) & $0.4(0.1-1.9)$ \\
\hline Donka & 77 & $(81.1)$ & $2.2(1.2-4.2)$ & & 54 & $(56.8)$ & $1.8 *(1.1-3.1)$ & $1.6(0.9-2.7)$ & 86 & $(90.5)$ & $0.3(0.9-1.0)$ \\
\hline \multicolumn{12}{|l|}{ Sex } \\
\hline Female & 116 & $(77.3)$ & $1.8 * *(1.1-3.1)$ & $1.7 * *(1.0-2.9)$ & 72 & $(48.0)$ & $0.8(0.5-1.3)$ & & 140 & (93.3) & $0.8 *(0.3-2.1)$ \\
\hline \multicolumn{12}{|l|}{ Age range } \\
\hline$\leq 28$ years & 75 & $(67.6)$ & $1-$ & & 50 & $(45.0)$ & $1-$ & & 108 & $(97.3)$ & $1-$ \\
\hline$>28$ years & 117 & $(75.0)$ & $1.4(0.8-2.5)$ & & 84 & (53.8) & $1.4(0.9-2.3)$ & & 143 & (91.7) & $0.3(0.1-1.1)$ \\
\hline \multicolumn{12}{|l|}{$\begin{array}{l}\text { Professional } \\
\text { status }\end{array}$} \\
\hline Nurse & 63 & $(67.7)$ & $1-$ & & 46 & $(49.5)$ & $1-$ & & 86 & $(92.5)$ & $1-$ \\
\hline Doctor & 62 & $(79.5)$ & $1.8(0.9-3.7)$ & & 42 & $(53.8)$ & $1.2(0.7-2.2)$ & & 72 & (92.3) & $1.0(0.3-3.0)$ \\
\hline \multicolumn{12}{|l|}{ Ebola training } \\
\hline No & 53 & $(57.6)$ & $1-$ & $1-$ & 34 & $(37.0)$ & $1-$ & $1-$ & 89 & $(96.7)$ & $1-$ \\
\hline Yes & 139 & (79.4) & $2.8 * * *(1.6-4.9)$ & $2.7 * * *(1.6-4.8)$ & 100 & (57.1) & $2.3 * *(1.4-3.8)$ & $2.2 * *(1.3-3.8)$ & 162 & (92.6) & $0.4(0.1-1.5)$ \\
\hline
\end{tabular}

OR: Odd ratio; AOR: Adjusted Odd ratio; *: $\mathrm{p}<.1 ; * *: \mathrm{p}<.05 ; * * *: \mathrm{p}<.001$.

\section{Discussion}

It is important for health care workers to understand the main aspects of Ebola Virus Disease (EVD) to recognize rapidly a case, to provide appropriate medical care and to prevent transmission. Nearly three out of four health care workers in this study (71.9\%) had a good understanding of key aspects of Ebola transmission and prevention. However, a significant percentage of carers had poor knowledge of the number of confirmed EVD cases (12\%), Ebola characteristics (0.7\%), EVD differential diagnosis and Malaria (27\%) and treatments of EVD under test (4.7\%). Jalloh [15] showed in a study that a substantial number of health care workers in Guinea had misconceptions about the transmission of the 
Ebola virus or expressed reluctance about the proximity of Ebola survivors. These data show the level of health promotion efforts needed to prevent or quickly control future outbreaks. In this study, as in the one conducted in Nigeria [16], having received training in EVD was associated with a good knowledge of EVD. Carlos [17] showed that although training improves knowledge about EVD, those on transmission remained suboptimal. Health authorities will have the challenge of maintaining a continuing level of training for health care workers during the epidemic-free period to allow new and old acquaintances to update their knowledge of EVD. Special emphasis should be given to female health care workers for these trainings. Without or in association with the training, self-documentation would be among the best channels of knowledge acquisition. A majority $(94 \%)$ of health care workers had a good attitude. A positive attitude level was found in $76.7 \%$ of medical staff in Ethiopia in 2016 [18]. However, the fear of contracting the disease and the lack of information on the procedures to follow in the face of a suspected Ebola case produce negative attitudes. Messages aimed at changing misconceptions about the transmission and prevention of the Ebola virus should rigorously promote the health. In this study, factors associated with a good attitude were not identified.

One in two health care workers $(50.2 \%)$ had good practice in this study. Similar trends of $45.7 \%$ and $64.7 \%$ were observed in Nigeria [19] and Ethiopia [20], respectively. The low percentage of health care workers who agreed to take part in the vaccine trial, correctly practiced hand washing for a while and adhering to the principle of using gloves, contributed to this level of practice. The results of the vaccine trial $[20,21]$ may be of interest to health care staff in response to outbreaks of Ebola virus disease. Organizing training for health care workers will provide better practice. A better organization of the INSE has certainly allowed this service to have a better practice for the EVD.

This study has some limitations. Indeed, it is not excluded that some participants were able to provide satisfactory answers to the recommendations rather than their real opinions. Also, the sample of health care workers was not representative of the staff of many private structures in Conakry. Despite these limitations, the results obtained provide important information to guide health communication efforts that can help control a future outbreak of the EVD epidemic.

\section{Conclusion}

The occurrence of the EVD epidemic in Guinea was a turning point for health care workers to acquire knowledge, new attitudes and practices through the training received. However, this study showed lack of knowledge, attitude and practice among health care workers. For this reason, it is relevant to further strengthen training to strengthen the capacity of health care providers and strengthen infections control measures.

\section{Authors' Contribution}

CA: conceptualized the study and design, did the entire data analysis

TMS and DIS: Did the interpretation of the result

TA, DA, and SS: Wrote the discussion and conclusion aspect of the article

GT, DAT and KMK: Wrote the introduction and abstract

MB: Coordinated field data collection and entry into computer statistical software

\section{Conflict of Interest}

No conflict of interest was reported by the authors.

\section{References}

[1] Baize S, Pannetier D, Oestereich L, Rieger T, Koivogui L, Magassouba N, et al. Emergence of Zaire Ebola Virus Disease in Guinea. N Engl J Med. 2014; 37: 1418-25.

[2] Thys S, Boelaert M. [The origin of Ebola: Biomedical approach versus popular interpretations in Macenta, Guinea]. Sante Publique. 2017; 29: 497-507.

[3] Gatherer D. The 2014 Ebola virus disease outbreak in West Africa. J Gen Virol. 2014; 95: 1619-24.

[4] Simon-Loriere E, Faye O, Faye O, Koivogui L, Magassouba N, Keita $S$, et al. Distinct lineages of Ebola virus in Guinea during the 2014 West African epidemic. Nature. 2015; 524: nature14612.

[5] Organisation mondiale de la Santé. Rapport de situation: Maladie à virus Ebola 2 juin 2016 [Internet]. WHO. 2016. Available from: http://www.who.int/csr/disease/ebola/fr/.

[6] Elston JWT, Cartwright C, Ndumbi P, Wright J. The health impact of the 2014-15 Ebola outbreak. Public Health. 2017; 143: $60-70$.

[7] Pellecchia U, Crestani R, Decroo T, Bergh RV den, Al-Kourdi Y. Social Consequences of Ebola Containment Measures in Liberia. PLOS ONE. 2015; 10: e0143036.

[8] Organisation mondiale de la Santé. Maladie à virus Ebola [Internet]. WHO. 2017. Available from: http://www.who.int/mediacentre/factsheets/fs103/fr/.

[9] Delamou A, Beavogui AH, Kondé MK, van Griensven J, De Brouwere V. Ebola: better protection needed for Guinean health-care workers. Lancet. 2015; 385: 503-4.

[10] Ngatu NR, Kayembe NJ-M, Phillips EK, Okech-Ojony J, Patou-Musumari M, Gaspard-Kibukusa M, et al. Epidemiology of ebolavirus disease (EVD) and occupational EVD in health care workers in Sub-Saharan Africa: Need for strengthened public health preparedness. J Epidemiol. 2017; 27: 455-61.

[11] Nkoghé D, Formenty P, Nnégué S, Mvé MT, Hypolite I, Léonard $\mathrm{P}$, et al. Recommandations pratiques pour la prise en charge sur le terrain des patients infectés par le virus Ebola. Med Trop. 2004; 64: 199-204.

[12] Valour F, Perpoint T, Gerbier-Colomban S, Ronin V, Potinet V, Loch J-BL, et al. Healthcare workers' knowledge, attitudes and practices relating to Ebola virus disease. J Hosp Infect. 2017; 97: 101-3. 
[13] Touré A, Traoré FA, Sako FB, Delamou A, Tonguino FS, Sylla D, et al. Knowledge, attitudes, and practices of health care workers on Ebola virus disease in Conakry, Guinea: A cross-sectional study. J Public Health Epidemiol. 2016; 8: 126.

[14] Vailaya C, Kumar S, Moideen S. Ebola virus disease: practices health care professionals in a Tertiary Care Hospital. J Pub Health Med Res. 2014; 2 (2): 13-8.

[15] Jalloh MF, Robinson SJ, Corker J, Li W, Irwin K, Barry AM, et al. Knowledge, Attitudes, and Practices Related to Ebola Virus Disease at the End of a National Epidemic - Guinea, August 2015. MMWR Morb Mortal Wkly Rep. 2017; 66: 1109-15.

[16] Otu A, Ebenso B, Okuzu O, Osifo-Dawodu E. Using a mHealth tutorial application to change knowledge and attitude of frontline health workers to Ebola virus disease in Nigeria: a before-and-after study. Hum Resour Health [Internet]. 2016. Available from: https://www.ncbi.nlm.nih.gov/pmc/articles/PMC4751664/.

[17] Carlos C, Capistrano R, Tobora CF, Aumentado C, Suy LL, Hall J, et al. Hospital preparedness for Ebola virus disease: a training course in the Philippines. West Pac Surveill Response J. 2015; 6: 33-43.
[18] Meskele LB, Fereja TH. Assessment of knowledge attitude and practice about Ebola virus disease (EVD) among health care professionals (HCP) at Adama hospital medical college (AHMC) Oromia region Ethiopia. Int J Adv Multidiscip Res. 2016; 3 (1): 21-30.

[19] Iliyasu G, Ogoina D, Otu AA, Dayyab FM, Ebenso B, Otokpa D, et al. A Multi-Site Knowledge Attitude and Practice Survey of Ebola Virus Disease in Nigeria. Chowell G, editor. PLOS ONE. 2015; 10: e0135955.

[20] Gsell P-S, Camacho A, Kucharski AJ, Watson CH, Bagayoko A, Nadlaou SD, et al. Ring vaccination with rVSV-ZEBOV under expanded access in response to an outbreak of Ebola virus disease in Guinea, 2016: an operational and vaccine safety report. Lancet Infect Dis [Internet]. 2017. Available from: http://www.thelancet.com/journals/laninf/article/PIIS14733099 (17)30541-8/abstract.

[21] Walldorf JA, Cloessner EA, Hyde TB, MacNeil A, CDC Emergency Ebola Vaccine Taskforce. Considerations for use of Ebola vaccine during an emergency response. Vaccine. 2017; DOI: 10.1016/j.vaccine.2017.08.058. 